\title{
Kontribusi Modal Sosial dalam Penerapan Manajemen Pengetahuan Usaha Kecil dan Menengah Kluster Kerajinan di Bogor
}

\author{
Social Capital Contribution for the Implementation of Knowledge Management in Small and Medium \\ Enterprises Cluster Craft in Bogor
}

\author{
Anggraini Sukmawati ${ }^{* 1}$ dan Lindawati Kartika ${ }^{* 1}$
}

${ }^{1}$ Departemen Manajemen, Fakultas Ekonomi dan Manajemen Institut Pertanian Bogor Jl. Kamper Kampus IPB Darmaga, Bogor 16680

\begin{abstract}
ABSTRAK
Aktivitas dari kunjungan wisatawan memberikan kesempatan kepada Usaha Kecil Menengah (UKM) untuk berdiri, sehingga menyebabkan UKM di Kota Bogor yang terkenal sebagai kota wisata terus meningkat. Namun, sebagian besar sumber daya manusia (SDM) di UKM berpendidikan rendah, dengan keahlian teknis, kompetensi, kewirausahaan dan manajemen sederhana. Kegagalan dalam memanfaatkan potensi sentra untuk mengembangkan organisasi dan modal sosial yang dimiliki UKM menunjukkan bahwa UKM masih menghadapi masalah SDM bermutu rendah. Di sisi lain, pengetahuan dari anggota organisasi perlu dimutakhirkan dan ditransfer agar pengetahuan tersebut tetap memiliki nilai terpadu dengan visi dan misi organisasi. Berdasarkan kebutuhan tersebut, terdapat sebuah pendekatan dalam mengelola pengetahuan yang dikenal sebagai manajemen pengetahuan. Oleh karena itu, penelitian ini bertujuan (1) menganalisis karakteristik modal sosial yang dimiliki organisasi UKM Bogor; (2) menganalisis karakteristik manajemen pengetahuan di organisasi UKM Bogor; (3) menganalisis kontribusi dan peran modal sosial pada implementasi manajemen pengetahuan organisasi UKM Bogor; dan (4) menganalisis hubungan peubah modal sosial dengan dengan peubah penerapan manajemen pengetahuan organisasi UKM Bogor. Penelitian ini menggunakan analisis Partial Least Square.
\end{abstract}

Kata kunci: manajemen pengetahuan, modal sosial, usaha kecil menengah

\section{ABSTRACT}

Activities of tourist visit provide opportunities for small and medium enterprises (SMEs) to stand, making the city of Bogor as one of the city that has an increasing number of SME's. Failure to exploit the potential of the center to develop its organization and social capital owned SME's indicate that SME's still face problems of low quality human resources. SME's mostly poorly educated human resources with technical expertise, competence, entrepreneurship and management are modest. On the other hand the knowledge inherent in members of an organization need to be updated and transferred to still have a value that is integrated with the vision and mission of the organization. On the basis of need, there is a knowledge management approach known as knowledge management.This study aims to (1) analyze the characteristics of social capital owned SME's organizations Bogor, (2) analyze the characteristics of knowledge management in Bogor SME's organization, (3) analyze the contribution and role of social capital on organizational knowledge management implementation, (4) analyze the relationship between social capital variables with the variables of organizational knowledge management practices of SME's Bogor. This study used structural equation modeling (SEM) analysis.

Key words: social capital, knowledge management, small and medium enterprise

\footnotetext{
*) Korespondensi:

Jl. Kamper Kampus IPB Darmaga, Bogor 16680; Telp. +62-0251-8626435

e-mail: anggrainism@gmail.com; lindawati.kartika@gmail.com
} 


\section{PENDAHULUAN}

Usaha Kecil dan Menengah (UKM) di Indonesia mencapai pertumbuhan yang menggembirakan dalam periode tahun 2010-2011, yaitu sebesar 4,25 persen. Disamping itu, UKM mampu menyerap tenaga kerja 3,04\% pada periode tahun 2009-2010 dan meningkat drastis pada periode selanjutnya 5,57\% (Kementerian Koperasi dan UKM, 2012).

Kota Bogor telah dan masih memberikan daya tarik besar bagi para wisatawan, yaitu tergambar dari tingkat kunjungan wisatawan ke kota Bogor di tahun 2011 yang mencapai 3.264.169 orang yang terdiri dari 3.112.414 wisatawan lokal dan 151.755 wisatawan mancanegara. Dengan demikian, kunjungan wisatawan tahun 2011 tumbuh $10,02 \%$ dibandingkan kunjungan wisatawan di tahun 2010 yang mencapai 2.967.426 orang. Perbandingan jumlah wisatawan tahun 2010-2011 dapat dilihat pada Gambar 1. Dengan peningkatan wisatawan asing dan domestik memberikan peluang kepada UKM Kerajinan untuk berdiri secara berkelanjutan. Hal ini dikarenakan kegiatan pariwisata meningkatkan pembelian oleh-oleh yang biasanya didominasi oleh kerajinan daerah setempat. Begitu pula dengan kota Bogor dengan meningkatkan wisatawan, sehingga berpeluang untuk meningkatkan omzet UKM Kerajinan Bogor.

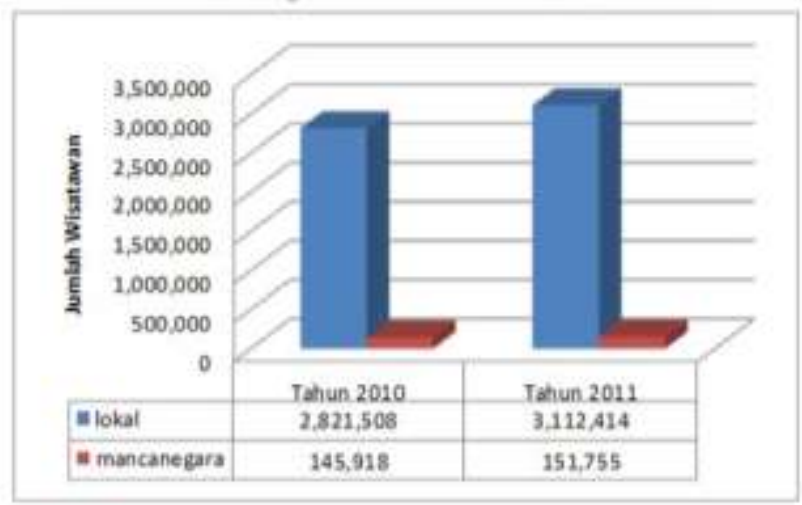

Gambar 1. Grafik perbandingan jumlah wisatawan yang berkunjung ke Bogor tahun 2010-2011 (Dinas Kebudayaan dan Pariwisata Kota Bogor, 2012)

Berdasarkan data yang diperoleh dari Kantor Koperasi dan UMKM Bogor, omzet yang peroleh UKM yang ada di Bogor selama tahun 2010-2011 mengalami peningkatan. Secara lengkap ditampilkan pada Tabel 1.
Kegagalan dalam memanfaatkan potensi sentra untuk mengembangkan organisasinya dan modal sosial yang dimiliki UKM mengindikasikan bahwa UKM masih menghadapi persoalan rendahnya mutu sumber daya manusia (SDM). Kebanyakan SDM UKM berpendidikan rendah dengan keahlian teknis, kompetensi, kewirausahaan dan manajemen seadanya. Di sisi lain pengetahuan yang melekat pada anggota suatu organisasi perlu dimutakhirkan dan ditransfer agar tetap memiliki nilai yang terpadu dengan visi dan misi organisasi. Atas dasar kebutuhan ini maka muncul pendekatan pengelolaan pengetahuan yang dikenal dengan manajemen pengetahuan (knowledge management).

Pengetahuan telah lama dikenal sebagai sumber daya organisasi yang sangat bernilai bagi pertumbuhan bisnis dan keunggulan kompetitifnya. Namun, masih banyak organisasi yang belum memiliki semua pengetahuan yang dibutuhkan dalam lingkup bisnisnya, serta bergantung pada sumber eksternal organisasi dan individu untuk mengakuisi pengetahuan (Wasko, 2005). Dalam konsteks manajemen pengetahuan, akuisisi pengetahuan seharusnya tidak hanya dari sumber eksternal, tetapi juga dari sumber-sumber internal organisasi. Akuisisi pengetahuan secara internal dapat dilakukan dengan berbagi pengetahuan sesama karyawan dalam suatu organisasi.

Di sisi lain, berbagi pengetahuan dalam dunia kerja memerlukan modal sosial (social capital) agar efektif. Modal sosial merupakan aset yang terbentuk dari relasi dan jejaring sosial yang tertanam dalam relasi antar individu, komunitas dan jejaring (Leana \& Van Buren, 1999; Tsai \& Ghosal, 1998). Modal sosial merupakan perspektif penting dan relatif baru. Ini adalah sumber daya produktif yang dinikmati oleh organisasi selama ada relasi, tetapi menghilang ketika relasi tidak ada lagi.

Penelitian ini bertujuan: (1) menganalisis karakteristik modal sosial yang dimiliki UKM Bogor; (2) menganalisis karakteristik manajemen pengetahuan yang ada di UKM Bogor; (3) menganalisis kontribusi dan peranan modal sosial terhadap penerapan manajemen pengetahuan organisasi dan (4) menganalisis hubungan antara peubah modal sosial dengan peubah penerapan manajemen pengetahuan di UKM Bogor. 


\section{METODOLOGI}

Manajemen pengetahuan adalah proses sistematis untuk menemukan, memilih, mengorganisasikan, menyarikan dan menyajikan informasi dengan cara tertentu yang dapat meningkatkan penguasaan pengetahuan dalam suatu bidang kajian spesifik (Probst et al., 2000). Komponen utama manajemen pengetahuan yang diteliti adalah people, place dan content (Honeycutt, 2000). Manajemen pengetahuan membutuhkan orang kompeten sebagai sumber pengetahuan, tempat untuk melakukan diskusi dan isi diskusi yang bermutu. Dari ketiga komponen tersebut peran teknologi informasi memungkinkan menghilangkan batasan dan kendala mengenai tempat terjadinya diskusi (pertukaran informasi dan pengetahuan).

Putnam mengartikan modal sosial sebagai penampilan organisasi sosial seperti jaringanjaringan dan kepercayaan yang memfasilitasi adanya koordinasi dan kerjasama bagi keuntungan bersama. Menurut Fukuyama, modal sosial adalah kemampuan yang timbul dari adanya kepercayaan dalam sebuah komunitas. Modal sosial memiliki tiga dimensi, yaitu dimensi struktural, dimensi relasional dan dimensi kognitif (Permadi, 2002).

Jenis data yang digunakan adalah data primer dan sekunder. Penelitian ini menggunakan probability sampling, yaitu cluster sampling dan metode sensus atau complete enumeration. Cluster sampling yang digunakan berdasarkan jenis produk yang dihasilkan oleh UKM, yaitu kerajinan dan souvenir khas Bogor.

\section{Metode Analisis Data}

\section{Analisis Deskriptif}

Analisis deskriptif digunakan untuk mengetahui karakteristik responden pada penelitian melalui rataan skor dan untuk mengidentifikasikan karakteristik responden yang berpengaruh terhadap peubah pada penelitian. Pada penelitian ini peubah yang digunakan adalah konsep modal sosial dan komponen utama manajemen pengetahuan.

Tabel 1. Perkembangan UKM Tahun 2010-2011

\begin{tabular}{llll}
\hline No. & \multicolumn{1}{c}{ Uraian } & $\mathbf{2 0 1 0}$ & $\mathbf{2 0 1 1}$ \\
\hline 1. & Jumlah UKM & 32.578 & 32.578 \\
2. & Jumlah UKM yang terbina & 2.231 & 2.669 \\
& oleh Kankop & & \\
3. & Jumlah Tenaga Kerja & 60.262 & 60.804 \\
4. & Asset UKM & 601.088 .638 .224 & 606.498 .435 .968 \\
5. & Omzet UKM & 3.270 .346 .569 .000 & 3.309 .590 .727 .828 \\
\hline
\end{tabular}

Sumber: Dinas Koperasi dan UMKM Kota Bogor (2012).

Dimensi Struktural :

1. Kepadatan hubungan (density) menggambarkan ikatan jaringan (network ties).

2. Jaringan penghubung (connectivity).

3. Jenjang struktural (hierarchy).

4. Kecocokan organisasi (appropriable organization).

Dimensi Relational :

1. Norma-norma (norms).

2. Kepercayaan (trust).

3. Kewajiban (obligations).

4. Identifikasi (identifications).

Dimensi Kognitif :

1. Andil dalam pengkodean dan pembahasan (shared codes and languages).

2. Andil dalam naratif (shared narratizes). 


\section{Uji Validitas dan Uji Reliabilitas}

Pengujian validitas dan reliabilitas dapat langsung dilakukan dari Partial Least Square (PLS). Model PLS yang digunakan dalam penelitian ini adalah model reflektif. Pengujian validitas dan reliabilitas dalam model reflektif dilakukan dalam tiga pengujian, yaitu convergent validity, discriminant validity, dan composite reliability. Convergent validity dari model pengukuran reflektif indikator dinilai berdasar-kan korelasi antara item score/component score dengan construct score yang dihitung dengan PLS. Ukuran reflektif dikatakan tinggi jika berkorelasi lebih dari 0,70 dengan konstruk yang diukur.

\section{Pengolahan Data dan Analisis Data}

Penelitian ini menggunakan Structural Equation Modeling (SEM) yang merupakan model persamaan regresi linear berganda dengan tujuan menguji model pengukuran dan model struktural. Terdapat dua peubah utama dalam SEM yakni peubah tidak terukur (laten) dan peubah terukur (manifes). Peubah laten merupakan konsep abstrak yang hanya dapat diamati secara tidak langsung. Peubah terukur atau yang teramati merupakan peubah yang dapat diamati dan sering disebut sebagai indikator (Hair, 1995). Penelitian ini menggunakan dua peubah laten independen (eksogen) yaitu modal sosial serta manajemen pengetahuan sebagai peubah laten dependen (endogen).

Alat analisis yang digunakan dalam penelitian ini adalah Partial Least Square dengan bantuan software SmartPLS 2.0. Path Modelling Partial Least Square Model pada penelitian ini dapat dilihat pada Gambar 2.

Beberapa kriteria yang terdapat dalam pengolahan PLS dapat dilihat pada Tabel 2. Kriteria ini digunakan sebagai tolak ukur, apakah model dalam penelitian ini layak atau sesuai untuk digunakan atau tidak.

\section{HASIL PEMBAHASAN}

Berdasarkan wawancara dan pengamatan langsung omzet yang diperoleh oleh RF Craft, Bogor Kreatif, Raq Craft dan Boneka Horta berbeda-beda. Tabel 3 menunjukkan besar omzet yang diperoleh oleh masing-masing UKM (RF Craft, Bogor Kreatif, Raq Craft dan Boneka Horta).

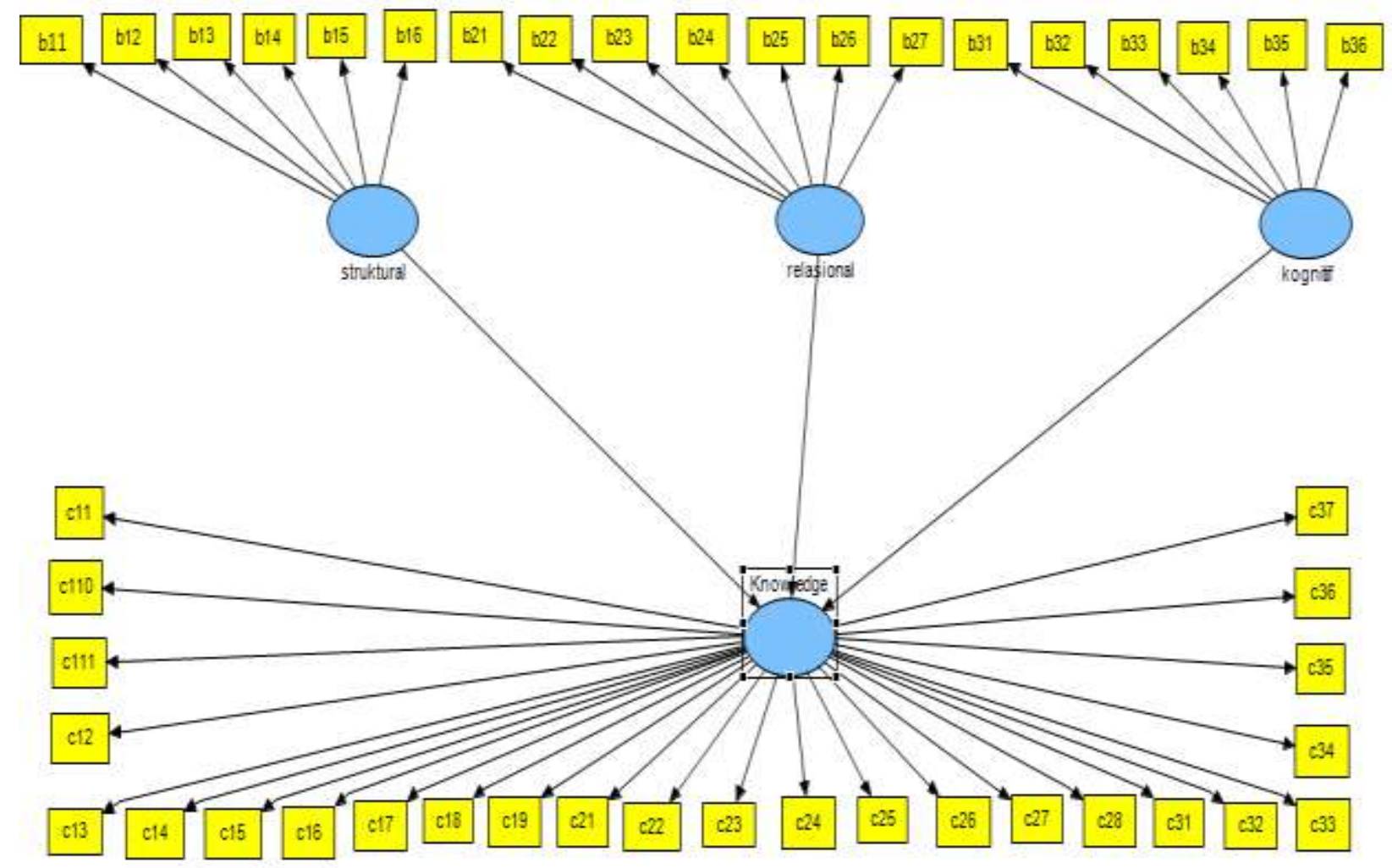

Gambar 2. Model Path Modelling PLS 
Tabel 2. Kriteria penilaian PLS

\begin{tabular}{|c|c|}
\hline Kriteria & Penjelasan \\
\hline \multicolumn{2}{|c|}{ Evaluasi model struktural } \\
\hline $\begin{array}{l}\text { R2 untuk variabel } \\
\text { laten endogen }\end{array}$ & $\begin{array}{l}\text { Hasil R² } 0.67,0.33 \text { dan } 0.19 \text { untuk variabel laten endogen dalam model struktural } \\
\text { mengindikasikan bahwa model "baik", "moderat", dan "lemah" }\end{array}$ \\
\hline $\begin{array}{l}\text { Estimasi koefisien } \\
\text { jalur }\end{array}$ & $\begin{array}{l}\text { Nilai estimasi untuk hubungan jalur dalam model struktural harus nyata. Nilai } \\
\text { nyata diperoleh dengan prosedur bootstrapping. }\end{array}$ \\
\hline f2 untuk effect size & $\begin{array}{l}\text { Nilai } \mathrm{f}^{2} 0.02,0,15 \text {, dan } 0,35 \text { dapat diinterpretasikan apakah prediktor peubah laten } \\
\text { mempunyai pengaruh lemah, medium atau besar pada tingkat struktural. }\end{array}$ \\
\hline $\begin{array}{l}\text { Relevansi prediksi } \\
\text { (Q2 dan } \mathrm{q} 2)\end{array}$ & $\begin{array}{l}\text { Prosedur blindfolding digunakan untuk menghitung: } Q 2=1-\Sigma D E D \Sigma D \mathrm{O} D \\
\mathrm{D} \text { adalah omission distance, E adalah sum of square of prediction errors, dan } \mathrm{O} \text { adalah } \\
\text { sum of squares of observation. Nilai Q2 di atas nol memberikan bukti bahwa model } \\
\text { memiliki predictive relevance (Q2 di bawah nol mengindikasikan model kurang } \\
\text { memiliki predictive relevance). Dalam kaitannya dengan } \mathrm{f} 2 \text {, dampak relatif model } \\
\text { struktural terhadap pengukuran peubah dependen laten dapat dinilai dengan: } q 2= \\
\text { Qincluded } 2-Q \text { excluded } 21-Q \text { inclu ded } 2\end{array}$ \\
\hline \multicolumn{2}{|c|}{ Evaluasi model pengukuran refleksif } \\
\hline Loading factor & Nilai loading factor harus di atas 0.7 \\
\hline Composite realibility & Composite realibility mengukur internal consistency dan nilainya harus di atas 0.6 \\
\hline $\begin{array}{l}\text { Validitas } \\
\text { diskriminan }\end{array}$ & $\begin{array}{l}\text { Nilai akar kuadrat dari AVE harus lebih besar daripada nilai korelasi antar peubah } \\
\text { laten }\end{array}$ \\
\hline Cross loading & $\begin{array}{l}\text { Merupakan ukuran lain dari validitas diskriminan. Diharapkan setiap blok } \\
\text { indikator memiliki loading lebih tinggi untuk setiap peubah laten yang diukur } \\
\text { dibandingkan dengan indikator untuk laten peubah lainnya }\end{array}$ \\
\hline \multicolumn{2}{|c|}{ Evaluasi model pengukuran formatif } \\
\hline $\begin{array}{l}\text { Signifikasi nilai } \\
\text { weight }\end{array}$ & $\begin{array}{l}\text { Nilai estimasi untuk model pengukuran formatif harus nyata. Tingkat nyata dinilai } \\
\text { dengan prosedur bootstrapping }\end{array}$ \\
\hline Multikolonieritas & $\begin{array}{l}\text { Peubah manifest dalam blok harus diuji apakah dapat multikolinearitas. Nilai } \\
\text { variance inflation factor (VIF) dapat digunakan untuk menguji hal ini. Nilai VIF di } \\
\text { atas 10, mengindikasikan terdapat multikolinearitas. }\end{array}$ \\
\hline
\end{tabular}

Tabel 3. Hasil omzet UKM kerajinan dan souvenir

\begin{tabular}{cll}
\hline No. & Nama UKM & \multicolumn{1}{c}{ Omzet per bulan (Rp) } \\
\hline 1. & RF Craft & 6.000 .000 \\
2. & Bogor Kreatif & $50.000 .000-100.000 .000$ \\
3. & Raq Craft & 5.000 .000 \\
4. & Boneka Horta & $50.000 .000-100.000 .000$ \\
\hline
\end{tabular}

RF Craft memiliki level manajemen Knowledge-aware (sadar akan kebutuhan manajemen pengetahuan, ada beberapa proses manajemen pengetahuan, ada teknologi dan ada isu tentang sharing informasi). Hal ini dikarenakan Walaupun usaha RF Craft masih skala mikro. Jumlah tenaga kerja yang dimiliki oleh RF Craft adalah berjumlah 4 orang termasuk owner. RF Craft tidak memiliki kualifikasi khusus dalam merekrut karyawan, hanya yang terpenting karyawan tersebut menyukai apa yang dikerjakan dan peduli pada lingkungan serta memiliki jiwa sosial.

Bogor Kreatif memiliki level manajemen Knowledge-aware (sadar akan kebutuhan manajemen pengetahuan, ada beberapa proses manajemen pengetahuan, ada teknologi dan ada isu tentang sharing informasi). Jumlah tenaga kerja yang dimiliki oleh Bogor Kreatif adalah berjumlah 11 orang termasuk owner. Bogor Kreatif tidak memiliki kualifikasi khusus dalam merekrut karyawan,

Raq Craft memiliki level manajemen Knowledge-chaotic (tak sadar konsep, tidak ada proses informasi dan tidak ada sharing pengetahuan). Jumlah tenaga kerja yang dimiliki oleh Raq Craft adalah berjumlah 3 orang termasuk owner. Raq Craft tidak memiliki kualifikasi khusus dalam merekrut karyawan, yang terpenting adalah teliti, rapi dan tekun. 
Boneka Horta memiliki level manajemen Knowledge-enable (memanfaatkan manajemen pengetahuan, mengadopsi standar, isu-isu berkaitan dengan budaya dan teknologi). Jumlah tenaga kerja yang dimiliki oleh Bogor Kreatif adalah berjumlah delapan orang termasuk owner. Untuk menjadi karyawan boneka horta karyawan diharuskan minimum memiliki pendidikan SMA dan yang paling penting adalah adanya keinginan untuk belajar dan mengikuti pelatihan yang ada

\section{Karakteristik UKM Kerajinan dan Souvenir}

Untuk menggambarkan hubungan antara karakteristik responden, yaitu lama bekerja dengan jenis kelamin, lama bekerja dengan usia, lama bekerja dengan pendidikan terakhir, lama bekerja dengan status pernikahan, lama bekerja dengan jumlah tanggungan, lama bekerja dengan pendapatan per bulan digunakan crosstabs. Berdasarkan hasil crosstabs, terlihat bahwa karyawan didominasi oleh karyawan yang bekerja selama 4-6 tahun berjenis kelamin lakilaki, berusia 21-25 tahun, dengan pendidikan terakhir SMP, berstatus belum menikah, tidak memiliki tanggungan dan berpendapatan per bulan >Rp1.500.000-Rp2.000.000.

\section{Persepsi Karyawan terhadap Modal Sosial}

Persepsi karyawan terhadap modal sosial yang telah dibentuk dalam pernyataan kuesioner dan nilai rataan skor. Nilai rataan skor tersebut menunjukkan persepsi karyawan setuju atau tidak terhadap pernyataan dalam kuesioner, dengan batasan nilai sebagai berikut: rentang nilai 1,00-1,75 menunjukkan persepsi sangat tidak setuju/sangat tidak baik/sangat rendah; rentang nilai 1,76-2,50 menunjukkan persepsi tidak setuju/tidak baik/rendah; rentang nilai 2,51-3,25 menunjukkan persepsi setuju/baik/tinggi dan rentang nilai 3,26-4,00 menunjukkan persepsi sangat setuju/sangat baik/sangat tinggi (Tabel 4).

Hasil penilaian persepsional karyawan, diperoleh rataan nilai skor 3,10. Hal ini menunjukkan bahwa karyawan menilai UKM tempat kerjanya telah memiliki modal sosial yang memadai. Secara berturut-turut dimensi relasional merupakan konsep yang memiliki skor tertinggi kemudian diikuti oleh dimensi struktural dan dimensi kognitif. Konsep dimensi kognitif termasuk pada skor yang terkecil sehingga UKM Bogor diharapkan dapat mengoptimalkan konsep kognitif karena dimensi kognitif dibutuhkan dalam shared codes and languages dan shared narrative.
Tabel 4. Persepsi karyawan terhadap modal sosial

\begin{tabular}{clcc}
\hline No. & Indikator & $\begin{array}{c}\text { Rataan } \\
\text { Skor }\end{array}$ & $\begin{array}{c}\text { Pernyataan } \\
\text { Jawaban }\end{array}$ \\
\hline 1 & $\begin{array}{l}\text { Dimensi } \\
\text { Struktural }\end{array}$ & 3,07 & \\
2 & $\begin{array}{l}\text { Dimensi } \\
\text { Relasional }\end{array}$ & 3,17 & Setuju \\
3 & $\begin{array}{l}\text { Dimensi } \\
\text { Kognitif }\end{array}$ & 3,06 & \\
\hline & Rataan Total & 3,10 & Setuju \\
\hline
\end{tabular}

\section{Persepsi Karyawan terhadap Komponen Mana- jemen Pengetahuan}

Persepsi karyawan terhadap komponen manajemen pengetahuan memiliki skor 2,96. Hal ini berarti komponen manajemen pengetahuan dinilai telah berjalan dengan baik menurut kondisi yang ada di UKM Bogor. Pada Tabel 5 dapat dilihat bahwa ketiga indikator memiliki skor rataan yang hampir sama, sehingga ketiganya berada pada rentang yang sama, maka diimplikasikan sama rata.

Tabel 5. Persepsi karyawan terhadap komponen manajemen pengetahuan

\begin{tabular}{llcc}
\hline No. & Indikator & $\begin{array}{c}\text { Rataan } \\
\text { Skor }\end{array}$ & $\begin{array}{c}\text { Pernyataan } \\
\text { Jawaban }\end{array}$ \\
\hline 1 & People & 2,95 & \\
2 & Place & 2,96 & Setuju \\
3 & Content & 2,96 & \\
\hline & Rataan Total & 2,96 & Setuju \\
\hline
\end{tabular}

\section{Analisis Path Modelling PLS}

Path Modelling PLS dalam penelitian ini digunakan untuk menganalisis besarnya pengaruh, menjelaskan ada atau tidaknya hubungan antar peubah laten, menganalisis konstruk yang dibentuk indikator reflektif, serta nyata atau tidaknya modal sosial terhdap manajemen pengetahuan.

\section{Uji Validitas dan Uji Reliabilitas Model}

Model PLS yang digunakan dalam penelitian ini adalah model reflektif. Pengujian validitas dan reliabilitas dalam model reflektif dilakukan dalam tiga pengujian, yaitu convergent validity, discriminant validity dan composite reliability. Convergent validity dari model pengukuran reflektif indikator dinilai berdasarkan korelasi antara item score/component score dengan construct score yang dihitung dengan PLS. Ukuran reflektif dikatakan tinggi, jika berkorelasi $>0,70$ dengan konstruk yang ingin diukur. Penelitian 
tahap awal dari pengembangan skala pengukuran nilai loading 0,50 sampai 0,60 dianggap cukup (Chin dalam Ghozali, 2008). Penelitian ini menggunakan ukuran reflektif 0,50 karena termasuk penelitian tahap awal. Model pengukuran awal dapat dilihat pada Gambar 3.

Untuk modal sosial dilakukan lima kali estimasi ulang dan indikator-indikator yang dihilangkan adalah b16, b22, b31, b34, b35 semua indikator tersebut memiliki nilai loading factor di bawah 0,50. Untuk komponen manajemen pengetahuan dilakukan sepuluh kali estimasi ulang. Sebelas indikator yang dihilangkan adalah c14, c17, c18, c19, c110, c111, c23, c33, c34 dan c37. Setelah seluruh indikator memiliki loading factor $>0,50$, maka convergent validity telah terpenuhi. Model setelah estimasi ulang dapat dilihat pada Gambar 4.
Berdasarkan tabel crossloading terlihat bahwa korelasi konstruk struktural dengan indikator b11, b12, b13 dan b14, b15 lebih tinggi dibandingkan korelasi antara indikator tersebut dengan konstruk lainnya. Korelasi konstruk relasional dengan indikator b21, b23, b24, b25 dan b26 lebih tinggi dibandingkan korelasi antara indikator tersebut dengan konstruk lainnya. Korelasi konstruk kognitif dengan indikator b32, b33, b36 lebih tinggi dibandingkan korelasi antara indikator tersebut dengan konstruk lainnya. Begitu pula dengan korelasi konstruk Knowledge (Manajemen Pengetahuan) dengan indikator c11, c12, c13, c15, c16, c21, c22, c24, c25, c26, c27, c31, c32 dan c36 lebih tinggi dibandingkan korelasi antara indikator tersebut dengan konstruk lainnya sehingga syarat discriminant validity telah terpenuhi.

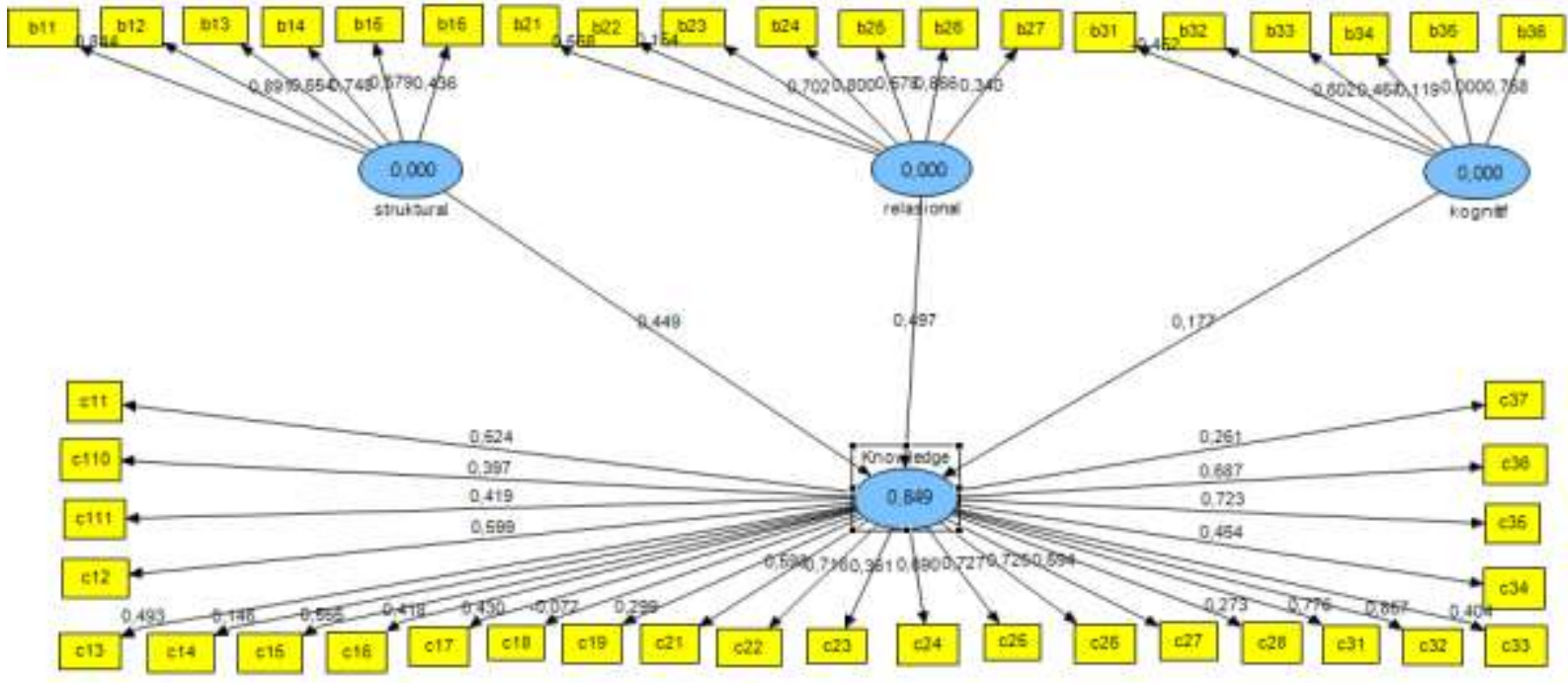

Gambar 3. Output grafis SmartPLS (sebelum estimasi ulang)

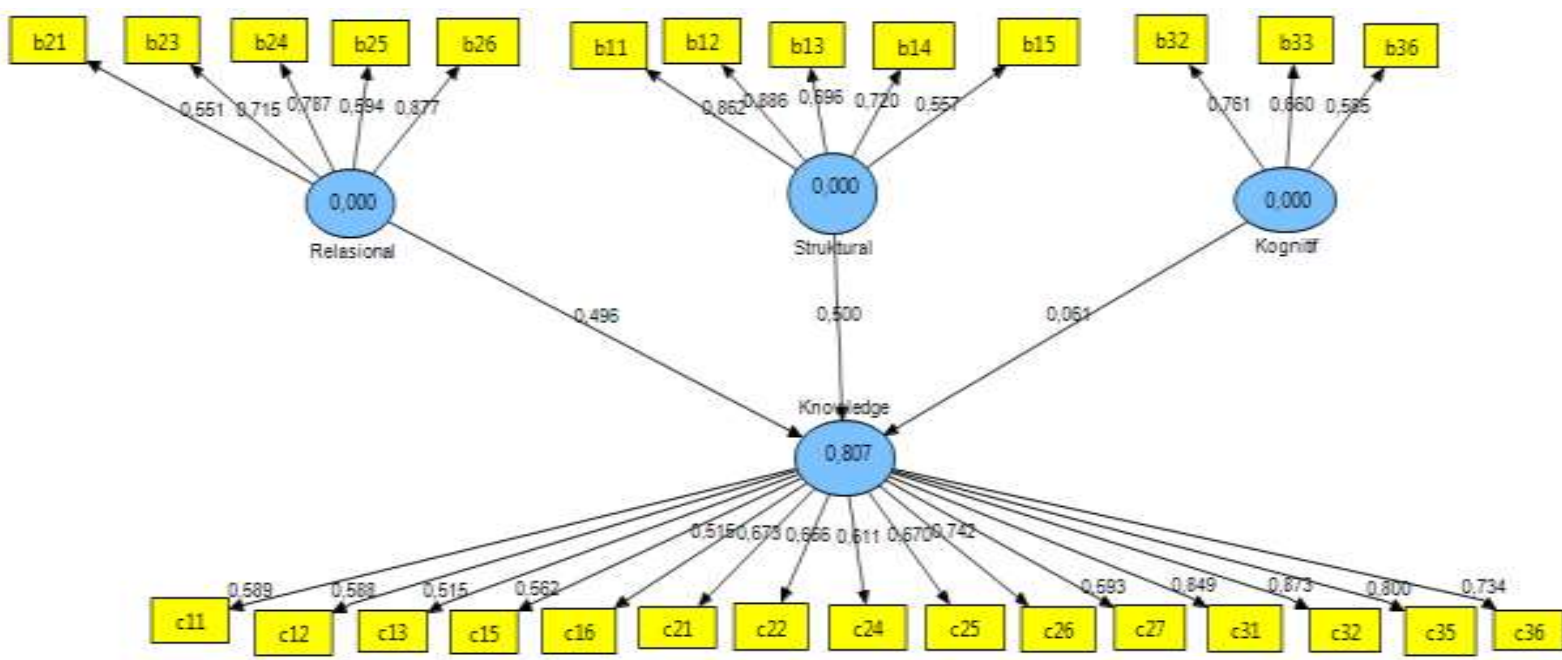

Gambar 4. Output grafis SmartPLS (setelah esti-masi ulang) 
Metode lain yang dapat digunakan untuk melihat discriminant validity adalah dengan membandingkan nilai Average Variance Extracted (AVE) setiap konstruk dengan korelasi antara konstruk dengan konstruk lainnya dalam model. Metode lain yang dapat digunakan untuk melihat discriminant validity adalah dengan membandingkan nilai AVE setiap konstruk dengan korelasi antara konstruk dengan konstruk lainnya dalam model. nilai akar AVE dari konstruk knowledge, kognitif, relasional dan struktural lebih besar dibandingkan nilai korelasi antara modal sosial (struktural, relasional, kognitif) dengan knowledge. Jadi semua konstruk dalam model telah memenuhi discriminant validity.

Uji reliabilitas konstruk dalam PLS dilakukan dengan dua kriteria, yaitu composite reliability dan cronbach alpha dari blok indikator yang mengukur konstruk. Konstruk knowledge, struktural, relasional dan kognitif telah memenuhi kriteria composite reliability karena nilai composite reliability maupun di atas 0,70. Untuk nilai cronbach alpha konstruk knowledge, struktural dan relasional memiliki nilai di atas 0,70 , sedangkan kognitif memiliki nilai di bawah 0,70, yaitu 0,38. Artinya, masing-masing konstruk reflektif memiliki reliabilitas yang baik. Perbandingan hasil Model 1 (sebelum estimasi) dan Model 2 (setelah estimasi) dapat dilihat pada Tabel 6 .

Model yang diuji sudah memenuhi syarat convergent validity, discriminant validity, validitas konstruk dan reliabilitas konstruk adalah model 2 (model setelah estimasi). Setelah model memenuhi asumsi convergent validity, discriminant validity, validitas konstruk dan reliabilitas konstruk, maka model dapat dapat dianalisis dan diinterpretasikan.

\section{Pengaruh Modal Sosial terhadap Manajemen Pengetahuan}

Tujuan utama dalam penelitian ini adalah untuk mengetahui besarnya pengaruh, arah hubungan, serta nyata atau tidaknya modal sosial yang dimiliki UKM kerajinan di Bogor terhadap pengembangan manajemen pengetahuan. Diantara ketiga dimensi modal sosial yang diuji, peubah dimensi struktural adalah peubah yang memiliki pengaruh paling besar dan nyata karena memiliki nilai koefisien dan t-value yang paling besar diantara yang lain, yaitu 0,500 dengan t-value 6,33 (Gambar 5).

Tabel 6. Perbandingan Hasil Model 1(sebelum estimasi) dan Model 2 (setelah estimasi)

\begin{tabular}{|c|c|c|c|c|c|}
\hline No. & Model 1 & Model 2 & Kriteria & Penjelasan & Hasil \\
\hline 1. & 0,85 & 0,81 & $\begin{array}{l}\mathrm{R}^{2} \text { untuk } \\
\text { peubah laten } \\
\text { endogen }\end{array}$ & $\begin{array}{l}\text { Hasil } \mathrm{R}^{2} \text { 0,67, 0,33, 0,19 } \\
\text { mengindikasikan "baik", moderat" } \\
\text { dan "lemah" }\end{array}$ & Model 1 \\
\hline 2. & $\begin{array}{l}\text { b16, b22, b31, b34, } \\
\text { b35 } \rightarrow<0,5\end{array}$ & Seluruhnya $>0,5$ & Loading factor & $\begin{array}{l}\text { Nilai loading factor di atas } 0,5 \\
\text { (model penelitian baru) }\end{array}$ & Model 2 \\
\hline 3. & $\begin{array}{l}\text { Knowledge }=0,90 \\
\text { Kognitif }=0,25 \\
\text { Relasioal }=0,79 \\
\text { Struktural =0,85 }\end{array}$ & $\begin{array}{l}\text { Knowledge }=0,92 \\
\text { Kognitif }=0,71 \\
\text { Relasioal }=0,83 \\
\text { Struktural }=0,86\end{array}$ & $\begin{array}{l}\text { Composite } \\
\text { realibility }\end{array}$ & $>0,7$ & Model 2 \\
\hline 4. & $\begin{array}{l}\text { Knowledge }=0,88 \\
\text { Kognitif }=0,21 \\
\text { Relasional }=0,71 \\
\text { Struktural }=0,79\end{array}$ & $\begin{array}{l}\text { Knowledge }=0,91 \\
\text { Kognitif }=0,38 \\
\text { Relasional }=0,75 \\
\text { Struktural }=0,81\end{array}$ & $\begin{array}{l}\text { Cronbach } \\
\text { alpha }\end{array}$ & $>0,7$ & Model 2 \\
\hline 5. & $\begin{array}{l}\text { 1. Nilai akar AVE } \\
>\text { nilai korelasi } \\
\text { laten } \\
\text { 2. Lebih besar }\end{array}$ & $\begin{array}{l}\text { 1. Nilai akar AVE } \\
\text { > nilai korelasi } \\
\text { laten } \\
\text { 2. Lebih besar }\end{array}$ & $\begin{array}{l}\text { Validitas } \\
\text { diskriminan }\end{array}$ & $\begin{array}{l}\text { 1. Nilai akar kuadrat dari AVE > } \\
\text { nilai korelasi laten } \\
\text { 2. Jika korelasi konstruk dengan } \\
\text { item pengukuran lebih besar } \\
\text { daripada ukuran konstruk } \\
\text { lainnya, maka ini menunjukkan } \\
\text { konstruk laten memprediksi } \\
\text { ukuran pada blok lebih baik } \\
\text { daripada ukuran pada blok } \\
\text { lainnya }\end{array}$ & Model 1 \\
\hline
\end{tabular}




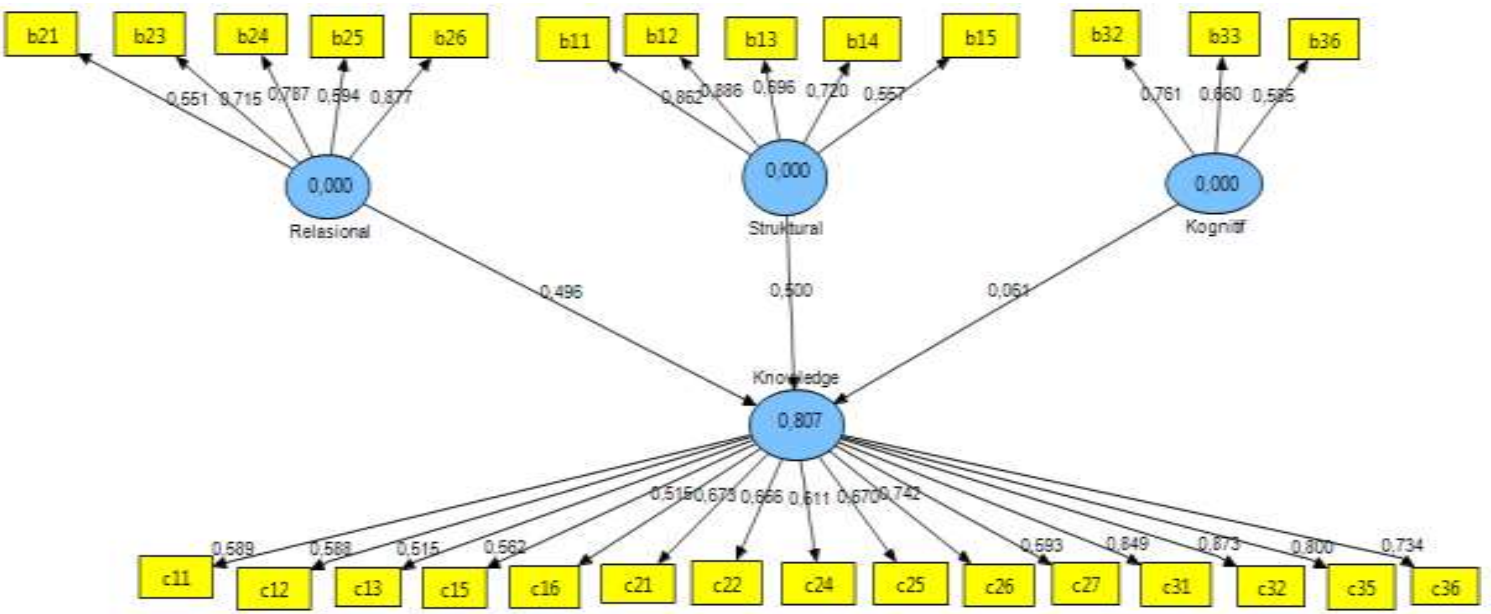

Gambar 5. Model pengaruh modal sosial terhadap manajemen pengetahuan

Hal ini menunjukkan bahwa meningkatnya penerapan dimensi struktural, akan meningkatkan keberhasilan implementasi manajemen pengetahuan pada UKM Kerajinan Bogor. Dimensi strukural tercermin dengan meningkatnya komunikasi dan hubungan karyawan dengan rekan kerja di luar unit, peningkatan penciptaan ide-ide kreatif yang dapat dipertanggungjawabkan. Hal ini sesuai dengan hasil penelitian Huang (2010) yang membuktikan bahwa modal sosial memperkuat produktivitas pengetahuan. Nilai koefisien dan t-value modal sosial terhadap manajemen pengetahuan dapat dilihat pada Tabel 7 .

Tabel 7. Nilai koefisien dan t-value modal sosial terhadap manajemen pengetahuan

\begin{tabular}{lcc}
\hline \multicolumn{1}{c}{ Konstruk } & Koefisien & t-value \\
\hline Kognitif -> Knowledge & 0,061 & 0,53 \\
Relasional -> Knowledge & 0,496 & 6,33 \\
Struktural -> Knowledge & 0,500 & 3,42 \\
\hline
\end{tabular}

\section{Pengaruh Dimensi Struktural terhadap Mana- jemen Pengetahuan}

Dimensi struktural modal sosial organisasi menunjuk pada keseluruhan pola hubungan antara aktor-aktor siapa yang dijangkau dan bagaiman kita menjangkau orang-orang tersebut. Model pengaruh dimensi struktural terhadap manajemen pengetahuan dapat dilihat pada Gambar 6.

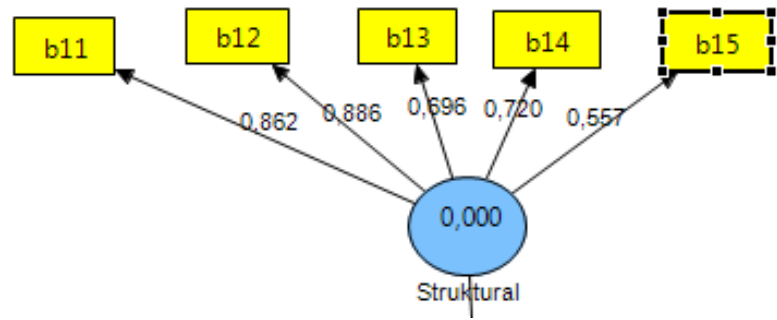

Gambar 6. Model pengaruh dimensi struktural terhadap manajemen pengetahuan

Berdasarkan hasil PLS, dimensi struktural terhadap manajemen pengetahuan diperoleh hasil bahwa dimensi struktural yang memiliki paling majemen pengetahuan Interpretasij2, yaitu karyawan selalu

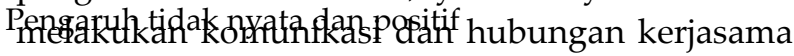
redengarh nyedtararkpbjstifdi luar unit kerja. b12

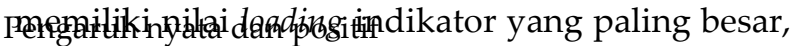
yaitu 0,89 dengan t-value 38,74. Artinya semakin meningkatkan komunikasi karyawan dan hubungan karyawan dengan rekan di luar unit kerja maka meningkatkan manajemen pengetahuan karyawan dalam hal content penciptaan ide-ide kreatif yang dapat dipertanggungjawabkan. Untuk lebih jelasnya hasil dapat dilihat pada Tabel 8.

Tabel 8. Nilai loading indikator dan t-value dimensi struktural terhadap manajemen pengetahuan

\begin{tabular}{rllll}
\hline Outer Model & Loading & Kriteria & t-value & Interpretasi \\
\hline b11 <- Struktural & 0,86 & 0,5 & 21,41 & \\
b12 <- Struktural & 0,89 & 0,5 & 38,74 & \\
b13 <- Struktural & 0,69 & 0,5 & 09,10 & Nyata dan pengaruh positif \\
b14 <- Struktural & 0,72 & 0,5 & 06,98 & \\
b15 <- Struktural & 0,56 & 0,5 & 04,26 & \\
\hline
\end{tabular}




\section{Pengaruh Dimensi Relasional terhadap Mana-} jemen Pengetahuan

Dimensi relasional berfokus pada hubungan khusus yang dimiliki perorangan, seperti respek dan pertemanan yang mempengaruhi perilaku mereka. Dalam penelitian ini dimensi relasional yang digunakan adalah berupa pertemanan (relatioships), perilaku yang menunjukkan kewajiban (obligation) dan kepercayaan diantara karyawan. Model pengaruh dimensi relasional terhadap manajemen pengetahuan dapat dilihat pada Gambar 7.

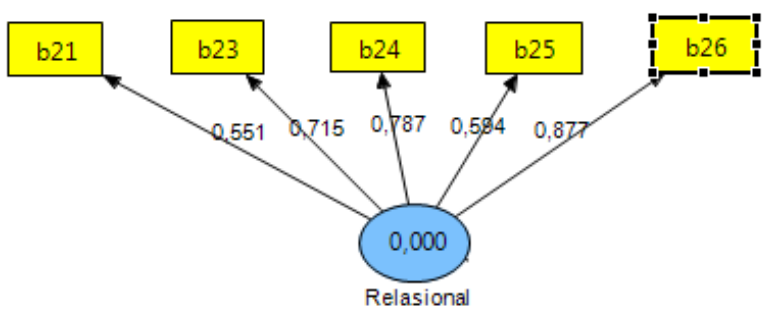

Gambar 7. Model pengaruh dimensi relasional terhadap manajemen pengetahuan

Indikator dari dimensi relasional yang paling besar memengaruhi manajemen pengetahuan adalah b26, karena memiliki nilai loading indikator paling besar, yaitu 0,87 dengan $t$-value 16,35 . Hal ini menunjukkan adanya korelasi yang nyata dan positif. Artinya semakin besar dimensi relasional yang tercermin dalam sikap karyawan dan rekan kerja selalu saling memberikan kritik yang membangun satu sama lain maka meningkatkan manajemen pengetahuan karyawan dalam peubah content, yaitu penciptaan ide-ide kreatif yang dapat dipertanggungjawabkan. Nilai outer loading masing-masing indikator dapat dilihat pada Tabel 9.

\section{Pengaruh Dimensi Kognitif terhadap Mana- jemen Pengetahuan}

Dimensi kognitif, yaitu sumber-sumber yang memberikan andil dalam representasi, interpretasi dan pengertian sistem diantara pihak yang berkepentingan. Dimensi ini mewakili nilai/aset yang penting dari modal sosial yang tidak didiskusikan dalam literatur utama tetapi memperoleh perhatian substansial yang diterima secara nyata dalam bidang strategi. Model pengaruh dimensi kognitif terhadap manajemen pengetahuan dapat dilihat pada Gambar 8.

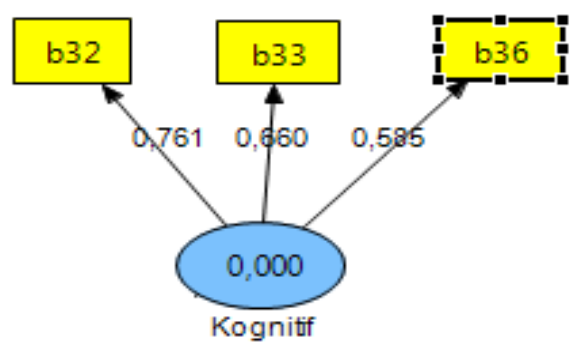

Gambar 8. Model pengaruh dimensi kognitif terhadap manajemen pengetahuan

Indikator dari dimensi kognitif yang paling besar memengaruhi manajemen pengetahuan adalah b32, karena memiliki nilai loading indikator paling besar, yaitu 0,76 dengan t-value 2,33. Hal ini menunjukkan adanya korelasi yang nyata dan positif. Artinya semakin besar dimensi kognitif tercermin dalam perilaku karyawan yang selalu berbagi cerita dan pengetahuan dengan rekan kerja maka meningkatkan keberhasilan penerapan manajemen pengetahuan. Perilaku karyawan dalam peubah content, yaitu penciptaan ide-ide kreatif yang dapat dipertanggungjawabkan. Nilai outer loading masing-masing indikator dapat dilihat pada Tabel 10.

Tabel 9. Nilai loading indikator dan t-value dimensi relasional terhadap manajemen pengetahuan

\begin{tabular}{ccccc}
\hline Outer Model & Loading & Kriteria & t-value & Interpretasi \\
\hline b21 <- Relasional & 0,55 & 0,5 & 4,08 & \\
b23 <- Relasional & 0,71 & 0,5 & 4,09 & \\
b24 <- Relasional & 0,79 & 0,5 & 6,45 & Nyata dan pengaruh positif \\
b25 <- Relasional & 0,59 & 0,5 & 4,76 & \\
b26 <- Relasional & 0,88 & 0,5 & 16,35 & \\
\hline
\end{tabular}

Tabel 10. Nilai loading indikator dan t-value dimensi kognitif terhadap manajemen pengetahuan

\begin{tabular}{rcccl}
\hline Outer Model & Loading & Kriteria & t-value & Interpretasi \\
\hline b32 <- Kognitif & 0,76 & 0,5 & 2,33 & \\
b33 <- Kognitif & 0,66 & 0,5 & 3,41 & Pengaruh nyata dan positif \\
b36 <- Kognitif & 0,58 & 0,5 & 2,39 & \\
\hline
\end{tabular}




\section{Pengaruh Manajemen Pengetahuan terhadap Indikator Manajemen Pengetahuan}

Manajemen pengetahuan adalah proses sistematis untuk menemukan, memilih, mengorganisasikan, menyarikan dan menyajikan informasi dengan cara tertentu yang dapat meningkatkan penguasaan pengetahuan dalam suatu bidang kajian spesifik. Atau secara umum manajemen pengetahuan adalah teknik mengelola pengetahuan dalam organisasi dalam rangka menciptakan dan meningkatkan keunggulan kompetitif. Manajemen Pengetahuan memiliki tiga komponen utama, yaitu people, place dan content. Model pengaruh manajemen pengetahuan terhadap indikator manajemen pengetahuan dapat dilihat pada Gambar 9.

Pada gambar secara keseluruhan dapat terlihat bahwa indikator c32 adalah indikator yang memiliki nilai loading paling besar, yaitu 0,87 sehingga indikator c32 dipengaruhi paling besar dalam manajemen pengetahuan. Artinya semakin besar manajemen pengetahuan yang diterapkan di UKM Kerajinan Bogor maka karyawan akan semakin mampu untuk menciptakan ide-ide kreatif dalam karyanya. Hasil nilai loading dan t-value per komponen peubah manajemen pengetahuan dapat dilihat pada Tabel 11, dengan rincian sebagai berikut:

1. People

Nilai loading indikator pada komponen people yang paling besar adalah c11 dan c12, yaitu 0,59 dengan t-value masing-masing 6,06 dan 6,21 . Hal ini menunjukkan korelasi nyata dan positif. Artinya bahwa karyawan yang berkompeten dalam UKM Kerajinan Bogor adalah karyawan yang memahami semua kegiatan yang berlangsung dalam organisasi dan memahami konsep dasar organisasi. Kegiatan organisasi yang dimaksud adalah bagaimana kegiatan produksi, pemasaran dan kegiatan lain yang berhubungan dengan produk dari UKM tersebut. Konsep dasar organisasi perlu dipahami oleh seluruh karyawan, misalnya konsep dasar dari UKM RF Craft adalah peduli pada lingkungan hampir sama dengan konsep dari boneka horta, yaitu go green dan stop global warming.

2. Place

Nilai loading indikator pada komponen place yang paling besar adalah c26, yaitu 0,74 dengan t-value 11,80. Hal ini menunjukkan korelasi nyata dan positif. Artinya bahwa karyawan dari masing-masing UKM merasa bahwa UKM Kerajinan Bogor (RF Craft, Bogor Kreatif, Raq Craft dan Boneka Horta) tempat dimana karyawan bekerja merupakan tempat terbaik bagi karyawan dalam menambah pengetahuannya, baik pengetahuan dalam membuat produk kerajinan, pengetahuan dalam pemasaran dan pengetahuan dalam pengelolaan keuangan khususnya Boneka Horta yang telah memiliki manajemen pengelolaan lebih terstruktur dibandingkan UKM yang lain. Hal ini sejalan dengan hasil penelitian Windarti dan Sukmawati (2011), keterlibatan dan pemberdayaan karyawan mampu meningkatkan keberhasilan penerapan manajemen pengetahuan

3. Content

Nilai loading indikator pada komponen content yang paling besar adalah c32, yaitu 0,87 dengan t-value masing-masing 16,68 . Hal ini menunjukkan korelasi nyata dan positif. Artinya bahwa semakin besar pengetahuan karyawan maka karyawan UKM Kerajinan Bogor akan semakin mampu untuk menciptakan ide-ide kreatif dalam pembuatan produk inovatif.

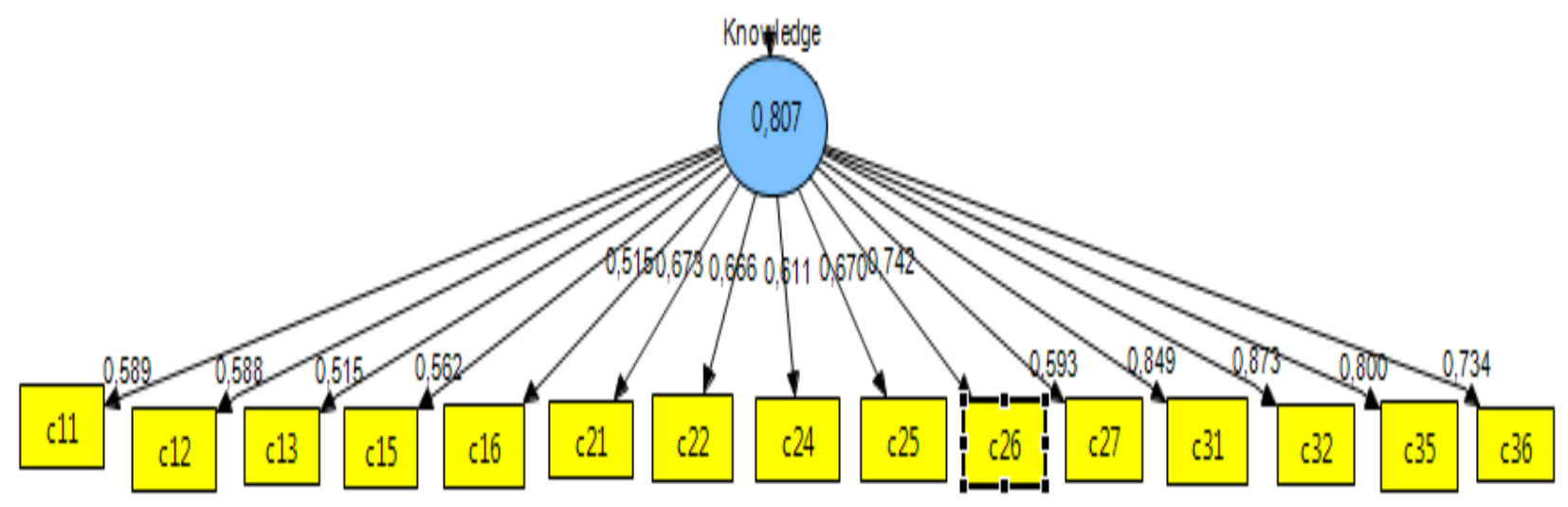

Gambar 9. Model pengaruh manajemen pengetahuan terhadap indikator manajemen pengetahuan 
Tabel 11. Hasil nilai outer loading dan t-value konstruk manajemen pengetahuan

\begin{tabular}{|c|c|c|c|c|c|c|}
\hline Konstruk & Variabel & Indikator & Loading & t-value & Hasil & Keterangan \\
\hline \multirow{15}{*}{$\begin{array}{l}\text { Manajemen } \\
\text { Pengetahuan }\end{array}$} & \multirow[t]{5}{*}{ People } & $\mathrm{c} 11$ & 0,59 & 6,06 & $\begin{array}{l}\text { Nyata dan } \\
\text { positif }\end{array}$ & $\begin{array}{l}\text { Pemahaman terhadap segala } \\
\text { kegiatan yang berlangsung dalam } \\
\text { UKM }\end{array}$ \\
\hline & & c12 & 0,59 & 6,21 & $\begin{array}{l}\text { Nyata dan } \\
\text { positif }\end{array}$ & $\begin{array}{l}\text { Pemahaman terhadap konsep dasar } \\
\text { UKM }\end{array}$ \\
\hline & & c13 & 0,51 & 3,50 & $\begin{array}{l}\text { Nyata dan } \\
\text { positif }\end{array}$ & Pencapaian tujuan UKM \\
\hline & & c15 & 0,56 & 5,70 & $\begin{array}{l}\text { Nyata dan } \\
\text { positif }\end{array}$ & Pusat konsultasi pengetahuan \\
\hline & & c16 & 0,51 & 4,52 & $\begin{array}{l}\text { Nyata dan } \\
\text { positif }\end{array}$ & $\begin{array}{l}\text { Pengakuan terbaik terhadap kinerja } \\
\text { yang dihasilkan }\end{array}$ \\
\hline & \multirow[t]{6}{*}{ Place } & c21 & 0,67 & 4,69 & $\begin{array}{l}\text { Nyata dan } \\
\text { positif }\end{array}$ & $\begin{array}{l}\text { Kesempatan untuk memberikan } \\
\text { saran }\end{array}$ \\
\hline & & $\mathrm{c} 22$ & 0,67 & 5,33 & $\begin{array}{l}\text { Nyata dan } \\
\text { positif }\end{array}$ & $\begin{array}{l}\text { Kesempatan untuk berdiskusi } \\
\text { dengan rekan kerja terkait } \\
\text { pekerjaan yang dilakukan }\end{array}$ \\
\hline & & c24 & 0,61 & 6,27 & $\begin{array}{l}\text { Nyata dan } \\
\text { positif }\end{array}$ & $\begin{array}{l}\text { Kesempatan untuk bertanya } \\
\text { mengenai pekerjaan }\end{array}$ \\
\hline & & c25 & 0,67 & 6,69 & $\begin{array}{l}\text { Nyata dan } \\
\text { positif }\end{array}$ & $\begin{array}{l}\text { Perolehan fasilitas diskusi yang } \\
\text { memadai }\end{array}$ \\
\hline & & c26 & 0,74 & 11,80 & $\begin{array}{l}\text { Nyata dan } \\
\text { positif }\end{array}$ & $\begin{array}{l}\text { UKM ini merupakan tempat terbaik } \\
\text { untuk menambah pengetahuan }\end{array}$ \\
\hline & & c27 & 0,59 & 5,17 & $\begin{array}{l}\text { Nyata dan } \\
\text { positif }\end{array}$ & $\begin{array}{l}\text { Tantangan untuk menambah } \\
\text { pengetahuan }\end{array}$ \\
\hline & \multirow[t]{4}{*}{ Content } & c31 & 0,85 & 17,33 & $\begin{array}{l}\text { Nyata dan } \\
\text { positif }\end{array}$ & $\begin{array}{l}\text { Kemampuan untuk memberikan } \\
\text { ide kreatif }\end{array}$ \\
\hline & & c32 & 0,87 & 16,68 & $\begin{array}{l}\text { Nyata dan } \\
\text { positif }\end{array}$ & $\begin{array}{l}\text { Kemampuan menciptakan ide } \\
\text { kreatif yang dapat } \\
\text { dipertanggungjawabkan }\end{array}$ \\
\hline & & c35 & 0,80 & 10,59 & $\begin{array}{l}\text { Nyata dan } \\
\text { positif }\end{array}$ & $\begin{array}{l}\text { Kemampuan untuk memberikan } \\
\text { saran yang membangun }\end{array}$ \\
\hline & & c36 & 0,73 & 9,35 & $\begin{array}{l}\text { Nyata dan } \\
\text { positif }\end{array}$ & $\begin{array}{l}\text { Kemampuan untuk memberikan } \\
\text { solusi bagi permasalahan yang } \\
\text { dihadapi UKM }\end{array}$ \\
\hline
\end{tabular}

\section{KESIMPULAN}

Modal sosial yang yang dimiliki UKM kluster kerajinan di Bogor sudah memadai, yang dicerminkan dari keberadaan dimensi struktural dan dimensi relasional. Di sisi lain, Dimensi kognitif tidak berkontribusi nyata.

Secara keseluruhan, ketiga komponen manajemen pengetahuan sudah cukup terimplementasikan. Namun perlu dilakukan peningkatan terhadap people, terkait dengan karyawan UKM agar lebih berkompeten, sehingga menghasilkan kinerja maksimal. Selain itu, peningkatan terhadap place, terkait dengan ruang diskusi dan content, terkait dengan isi diskusi agar lebih menghasilkan ide-ide kreatif.

Hasil analisis kontribusi modal sosial dalam pengembangan manajemen pengetahuan ada pada tingkat goodness fit. Dimensi struktural dan dimensi relasional dari modal sosial memiliki pengaruh nyata dan positif, sedangkan dimensi kognitif memiliki pengaruh tidak nyata dan positif terhadap penerapan manajemen pengetahuan di UKM kerajinan di Bogor.

\section{DAFTAR PUSTAKA}

Ghozali, I. 2008. Structural Equation Modelling Me-tode Alternatif dengan Partial Least Square. Badan Penerbit Universitas Diponegoro. Semarang.

Hair, J.F, et al. 1995. Multivariate Data Analysis with Readings. New Jersey: Prentice-Hall.

Honeycutt, J. 2000. Knowledge Management Strategies: Strategi Manajemen Pengetahuan. PT Alex Media Komputindo, Jakarta.

Huang, Y.C. 2011. Intellectual capital and knowledge productivity: Tha Taiwan 
Biotech Industry. Managemnet Decision, 48(4): 580-599.

Leana, C. R. and Van Buren, H. 1999. Organizational social capital and employment practices. Academy of Management Review, 24(2): 538-555

Permadi, D.C. 2002. Analisis Pengaruh Modal Sosial Organisasi dan Modal Intelektual Organisasi Terhadap Keunggulan Organisasi (Studi Kasus di PT Polysindo Eka Perkasa dan PT Multi Karsa Investama, Texmaco Group, Kaliwungu-Kendal). Tesis. Undip-Semarang.

Probst G, S. Raub, K. Romhardt. 2000. Managing Knowledge: Building Blocks for Success. John Wiley \& Sons, Ltd. West Sussex
Wasko, M.M, S. Faraj. 2005. Why Should I Share? Examining Social Capital and Knowledge Contribution in Electronic Networks of Practice. MIS Quarterly, 29(1): 35-57

Windarti \& Sukmawati, A. Faktor-faktor kunci kesuksesan implementasi Manajemen Pengetahuan pada PT Unilever Indonesia, Tbk. Jurnal Manajemen dan Organisasi, 2(1): 13-26.

Tsai, W. \& Ghosal, S. 1998. Social capital and value creation: the role of intra firm networks. Academy of Management Journal, 41(4,): 464-476. 